\title{
A eclesialidade e a metodologia da ciência canônica
}

\author{
The Ecclesiality and the Methodology of Canonic Science
}

\section{Denilson Geraldo ${ }^{1}$}

Resumo: $\mathrm{O}$ ambiente pré-conciliar desfavorável ao direito canônico caracterizado pela doutrina do Ius Pubblicum Ecclesiasticum preparou a nova apresentação da ciência canônica com o decreto conciliar Optatam Totius que relacionou o direito canônico ao mistério da Igreja. A metodologia da ciência canônica, pressupondo a fundamentação eclesiológica, é jurídico-canônica e em diálogo interdisciplinar com as demais ciências, principalmente com a ciência teológica e a pastoral, mas conserva sua autonomia como ciência. A legislação que regulamenta as atividades das faculdades e dos institutos de direito canônico, a partir da Veritatis Gaudium, confirmam a metodologia jurídica da ciência canônica, bem como a fundamentação da ciência canônica no mistério da Igreja.

Palavras-chave: Metodologia Canônica, Ciência Canônica, Faculdade Eclesiástica, Direito Canônico, Veritatis Gaudium.
Abstract: The preconciliar environment unfavorable to canon law characterized by the doctrine of the Ius Pubblicum Ecclesiasticum prepared the new presentation of canon science with the conciliar decree Optatam Totius that related canon law to the mystery of the Church. The methodology of canonical science, assuming ecclesiological foundations, is juridical-canonical and in interdisciplinary dialogue with other sciences, mainly with theological and pastoral science, but retains its autonomy as a science. The legislation that regulates the activities of the faculties and institutes of canon law, starting with Veritatis Gaudium, confirms the juridical methodology of canonical science, as well as the foundation of canonical science in the mystery of the Church.

Keywords: Canonical Methodology, Canonical Science, Ecclesiastical Faculty, Canon Law, Veritatis Gaudium.

\footnotetext{
Doutor em Direito Canônico pela Pontifícia Universidade Lateranense de Roma; Professor do Instituto Superior de Direito Canônico Santa Catarina e do Instituto de Direito Canônico de Londrina. Diretor do Istituto San Vincenzo Pallotti (Roma). Editor da Revista Scientia Canonica e da Rivista Apostolato Universale.
} 


\section{Introdução}

O estudo da metodologia é sempre atual e urgente para a ciência canônica. O método é o meio, o caminho para a realização dos fins. A metodologia científica é o caminho a ser percorrido para que a ciência canônica possa servir à Igreja e à humanidade. É uma sistematização, uma organização de possibilidades em vista da produção científica, proporcionando um caminho, uma via de assimilação da ciência canônica.

Antes do Concílio Vaticano II, a ciência canônica foi caracterizada pela escola do Ius Pubblicum Ecclesiasticum que exerceu grande influência na preparação e no desenvolvimento inicial do próprio Concílio. No entanto, com desenvolvimento do Concílio e com a aprovação das constituições e dos decretos, evidenciou-se a limitação do Código de 1917 para responder às necessidades da Igreja em todos os seus setores. De certo modo, os documentos conciliares foram revogando paulatinamente o Código de 1917. Surge, então, o Código de Direito Canônico de 1983 com sua fundamentação ontológica no mistério da Igreja pelo decreto conciliar Optatam Totius.

$\mathrm{O}$ pontificado de Paulo VI se caracterizou, no que diz respeito à legislação canônica, pela defesa da capacidade potestativa da Igreja e pela necessidade eclesial do direito canônico. João Paulo II promulgou o novo Código e aprofundou muitos temas da nova legislação. Bento XVI evidenciou o sentido teológico da lei eclesiástica e nos deu uma hermenêutica da continuidade conciliar. Francisco mostra a finalidade pastoral da lei, mas conserva a necessidade de uma ciência canônica autônoma e com método próprio para melhor servir a Igreja. Para fundamentar tais posições, as alocuções ao Tribunal da Rota Romana foram fundamentais para indicar a estrada que a Igreja deveria realizar desde o pós-concílio.

Desse modo se aprofunda o conceito de método da ciência canônica que deve ser jurídico, fundamentado no mistério da Igreja e com autonomia científica, ou seja, que não se identifica com a teologia ou a pastoral. Assim, o conhecimento da ciência canônica se apresenta em quatro estágios: ontológico e axiológico, científico ou o científico-técnico, casuístico e prudencial. 
Contudo, é preciso também considerar a história da tradição jurídica, a história das fontes e das instituições para a aplicação do direito em um caso específico. Tendo em conta tais pontualizações, o trabalho do canonista é, fundamentalmente, elaborar em cada caso, com análise de conceitos, um direito coerente e harmonioso com o direito vigente na Igreja, ou seja, é necessário que o canonista produza, em cada caso apresentado pela vida eclesial, uma ciência canônica que será caracterizada pelo seu próprio método científico.

Entretanto, as características de interdisciplinaridade e de transdisciplinaridade da atual legislação sobre as faculdades e institutos de direito canônico, confirmadas pela Veritatis Gaudium, exigem atualmente que a ciência canônica dialogue, autonomamente, com as demais ciências. Para tanto, apresentamos algumas indicações, principalmente, aos estudantes que estão iniciando os estudos de direito canônico.

\section{0 ambiente eclesial desfavorável à ciência canônica}

No século XIX foi acentuada a independência da Igreja como sociedade soberana, dotada de um poder jurídico de origem divina, radicalmente autônomo a respeito do poder da autoridade política. Essa tendência foi objeto de uma tomada de posição constante, tanto no ensinamento doutrinal como na prática pastoral e diplomática da Santa $\mathrm{Sé}^{2}$.

O direito canônico, por sua vez, foi uma dimensão da vida eclesial criticada pelo protestantismo e pelo liberalismo laicista. Em sua defesa, a partir do século XVIII, teólogos e canonistas desenvolveram uma disciplina, dedicada à apologia da Igreja sob o perfil jurídico, chamada de Direito Público da Igreja. Foram os autores do Ius Publicum Ecclesiasticum que elaboraram a noção de "sociedade juridica-

2 Existe um amplo ensino a esse respeito na Idade Moderna, eficazmente resumido na sua evolução até aos nossos tempos por P. LOMBARDÍA, na sua síntese histórica in AA.VV. Derecho Eclesiástico del Estado Español, Pamplona, EUNSA 1980, 104-128. Entre os muitos documentos do magistério que defendem a Igreja como sociedade soberana frente ao Estado, tem importância fundante a encíclica Immortale Dei de Leão XIII, de 1 de Novembro de 1885 (in ASS 18 [1885-86] 162-175). 
mente perfeita", ou seja, a Igreja é uma sociedade plenamente autônoma com seus fins e com seus métodos, uma societas iuridice perfecta, assim como o é também o Estado na sua ordem ${ }^{3}$.

João XXIII convocou, em 25 de janeiro de 1959 na Basílica de São Paulo, um Sínodo diocesano para a cidade de Roma, um Concílio Ecumênico para a Igreja Universal e a reforma do Código de Direito Canônico ${ }^{4}$. Os documentos conciliares praticamente revogaram implicitamente os cânones do Código de 1917 ou, em muitos casos, limitaram suas orientações sem criar propriamente um novo direito. Os anos do pós-concílio assistiram a uma atividade legislativa intensa para a aplicação do Concílio, mas essa legislação geralmente pressupunha a vigência do Código de 1917 e articulava sobre ele novas leis inspiradas na doutrina conciliar ${ }^{5}$.

Neste processo de progressiva saída do Código de 1917 foi sendo formado o ambiente para a desvalorização do direito canônico, como um dos defeitos da Igreja que seria necessário corrigir. A ampla

3 Algumas obras mais relevantes do Ius Publicum Ecclesiasticum: A. OTTAVIANI, Institutiones iuris publici ecclesiastici, 4a ed. emendata et aucta iuvante prof. I. Damizia, 2 vol., Civitas Vaticana, Typis polyglottis vaticanis 1958-1960.; F. M. CAPPELLO, Summa Iuris Publici Ecclesiastici, Romae 1954; F. CAVAGNIS, Institutiones Iuris Publici Ecclesiastici, I, Romae 1906. Sobre o desenvolvimento histórico desta ciência, E. FOGLIASSO, "Il compito apologetico del Ius Publicum Ecclesiasticum", in Salesianum 7 (1945) 49-80; idem, "Compito e caratteristiche del Diritto Pubblico Ecclesiastico Interno" in Salesianum 12 (1950) 1-36; idem, "Compito e caratteristiche del Diritto Pubblico Ecclesiastico Esterno", in Salesianum 16 (1954) 218-257; A. DE LA HERA-CH. MUNIER, "Le Droit Public Ecclésiastique à travers ses définitions", en RDC 14 (1964) 32-63; L. SPINELLI, Il Diritto Pubblico Ecclesiastico dopo il Concilio Vaticano II, Milano 1985; J. CALVO, Teoría General del Derecho Público Eclesiástico, Santiago de Compostela 1968; F. VERA URBANO, Derecho Eclesiástico, I, Madrid 1990, 211-215; I. MARTÍN SÁNCHEZ, "La razón de ser y el objeto del Derecho Público Eclesiástico”, REDC 26 (1970) 39-59; G. CAPUTO, Introduzione allo studio del Diritto Canonico Moderno. I: Lo Jus Publicum Ecclesiasticum, Pádua 1978.

4 JOÃO XXIII, Sollemni allocutio, in Acta Apostolica Sedis, vol. LI (27 Februarii 1959), p. 68-69.

5 REDAELLI, C., La canonistica nel contesto delle scienze teologiche, in Quaderni di diritto ecclesiale, $n$. 10 (1997), 28-39, p. 29. 
crise no mundo e na Igreja dos anos 60 e $70^{6}$ teve suas causas específicas na rejeição do direito canônico que, em não poucos casos, redundou numa crise de aceitação do institucional, do visível, da historicidade da Igreja.

Paulo VI viveu intensamente esse período e alertou para duas perigosas consequências sobre a natureza da própria Igreja. A primeira consequência foi atribuir uma prioridade à comunidade e menosprezar o aspecto potestativo da Igreja, com acentuado descrédito das funções canônicas; e a segunda consequência foi a acusação de juridicismo à tradição e à praxe normativa da Igreja ${ }^{7}$. A discussão sobre a existência de um direito canônico chegou ao ponto de "qualificar como juridicismo, com certa reprovação e ironia, todas as suas solicitudes normativas, desqualificando, portanto, este aspecto da vida eclesiástica, quase como se as expressões imperfeitas da atividade legislativa na Igreja justificassem a reprovação e a abolição dessa atividade", ${ }^{\text {. }}$

$\mathrm{O}$ anti-juridicismo configurou-se na Igreja do imediato pósconcílio com diferentes características. A questão que vigorou foi a crítica a uma eclesiologia quase exclusivamente jurídica que foi dominante no período pré-conciliar. A eclesiologia do Corpo Místico de Cristo, a teologia do laicato, a eclesiologia do Povo de Deus, o tema da Igreja como sacramento de salvação, o tema da Igreja comunhão, a redescoberta nos primeiros anos do Concílio da colegialidade episcopal e o surgimento do movimento ecumênico foram decisivos para uma eclesiologia que não fosse exclusivamente jurídica.

Todos esses temas eclesiológicos sublinhavam os limites da eclesiologia de sociedade juridicamente perfeita, expressada no Código de 1917, nas orientações do Santo Ofício e no ensino acadêmico de

6 A síntese desses juízos, já nos anos 80, apareceu na entrevista de Joseph Ratzinger a Vittorio Messori no memorável A Fé Em Crise? O Cardeal Ratzinger se interroga, Editora EPU, São Paulo, 1985.

7 PAULO VI, Alocução ao Tribunal da Rota Romana: A função judiciária da Igreja ao serviço da verdade e da caridade, in L'Osservatore Romano, Edição Semanal em Português, ano II, n. 6, 7 de fevereiro de 1971, p. 1-2 e 4.

8 PAULO VI, Alocução ao Tribunal da Rota Romana: A justiça e a caridade no exercício da função judiciária da igreja, in Acta Apostolica Sedis 64 (1972) 202205; In L'Osservatore Romano, Edição Semanal em Português, ano III, n. 6, 6 de fevereiro de 1972, p. 3-4. 
Alfredo Ottaviani (1890-1979). A maneira como Alfrink (1900-1987) e os Padres Conciliares trataram Ottaviani na Aula Conciliar, foi o símbolo de uma ruptura com as formas do passado ${ }^{9}$. Contudo, este justo "anti-juridicismo" tendeu a identificar o jurídico com o antiteológico, o pré-conciliar e o anti-conciliar.

No pós-concílio a situação desfavorável do direito canônico, gerada no meio dos teólogos conciliares, encontrou apoio nos pastoralistas que, preocupados em encontrar soluções pastorais inovadoras para trazer novamente as pessoas à comunidade cristã e vencer o passo da secularização, não se identificavam com o direito canônico e os seus objetivos. A revalorização da Igreja local, o movimento missionário, o movimento ecumênico que conhecia um novo alento, sobretudo a reforma litúrgica, eram outras tantas realidades para avançar com soluções que nasciam da vida da Igreja, da diversidade imensa das circunstâncias culturais e geográficas e para as quais a pretensão de um direito universal parecia ser um empecilho e um peso.

Uma concepção jurídica de Igreja como sociedade perfeita praticamente ignorava sua natureza sobrenatural, a sua união ontológica a Cristo, a sua experiência pneumatológica, a sua condição sacramental, a sua historicidade como povo de Deus. O Concílio procurou responder às perguntas eclesiológicas de Montini na primeira sessão conciliar: "Que é a Igreja? Que faz a Igreja?", . Tais perguntas colocaram em destaque a situação eclesial descrita acima, de tal modo que se pode falar de uma nova eclesiologia, de uma eclesiologia do Vaticano II. Por isso, se impôs uma reflexão mais aprofundada sobre a natureza e a função do direito canônico na vida e na ação da Igreja.

9 A intervenção de Ottaviani, Secretário do Santo Ofício e Presidente da Comissão conciliar, na décima congregação geral da primeira sessão conciliar, falando longamente sobre a liturgia excedeu o seu tempo para se opor às propostas de alteração do ordinário da missa, à comunhão sob as duas espécies e à concelebração. O Cardeal Alfrink, arcebispo de Utrecht na Holanda, que nesse dia presidia a congregação geral, desligou-lhe o microfone. A interrupção foi aplaudida com entusiasmo pelos padres conciliares. Ver o episódio em G. ALBERIGO, Storia del Concilio Vaticano II, vol. II, Il Mulino, 1996, p. 150; Y. CONGAR, Mon journal du Concile, vol. I, Paris, Cerf, 2002, p. 163-165.

10 MONTINI, G. B., Intervenção na XXXIV Congregação Geral, in Acta Synodalia Sacrosancti Concilii Oecumenici Vaticano II, 5 de Dezembro de 1962, v. I, Periodus Prima, Pars IV, Congregationes Generales XXXI-XXXVI, p. 292. 
O Concílio foi um exercício para expor a natureza da Igreja através de cada pormenor dos seus documentos: liturgia, formação sacerdotal e vida dos padres, vida religiosa, teologia do laicato, ecumenismo, relações com o judaísmo, relações com as religiões, liberdade religiosa. No entanto, em muitos ambientes, a forma de explicar e propor o Concílio nas décadas de sessenta e setenta foi por contraposições, numa lógica de "corte epistemológico", de revolução copernicana: antes era de uma maneira, agora é de outra.

Todavia, Paulo VI recordou nas alocuções ao Tribunal da Rota Romana a natureza jurídica da Igreja e a relação do novo Código de Direito Canônico com o Concílio Vaticano II. Recordou Paulo VI que o próprio Concílio decretou a revisão do Código de Direito Canônico (Christus Dominus, n. 44) que atendesse a critérios mais ligados à missão pastoral da Igreja e às exigências legítimas da vida moderna. A Igreja, tutora vigilante da lei cristã e intérprete maternal da realidade humana como "ex intima hominis natura haurienda est iuris disciplina” (CÍCERO, De legibus II), não poderia ignorar a necessidade de um direito canônico ${ }^{11}$.

Diversamente, insistiu Paulo VI, na vertente do juridicismo e contrária ao ensinamento do Pontífice, a ciência canônica que prescindisse do espírito do Evangelho ou prevalecesse sobre a especulação teológica não corresponderia às orientações renovadoras do Concílio, pois a legislação eclesiástica está ligada à missão pastoral da Igreja e às exigências legítimas da vida moderna ${ }^{12}$.

11 PAUlO VI, Alocução ao Tribunal da Rota Romana, in Acta Apostolica Sedis 58 (1966) 152-155; In GOMES, SATURINO (Org.), Alocuções dos Papas Paulo VI e João Paulo II ao Tribunal da Rota Romana, Lisboa, Universidade Católica, 2006, p. 41-44.

12 PAULO VI, Alocução ao Tribunal da Rota Romana, in Acta Apostolica Sedis 61 (1969) 174-178; In GOMES, SATURINO (Org.), Alocuções dos Papas Paulo VI e João Paulo II ao Tribunal da Rota Romana, Lisboa, Universidade Católica, 2006, p. 55-59. 


\section{$2 \mathrm{O}$ fundamento conciliar do Código de Direito Canônico}

João Paulo II $^{13}$ em 1983, a poucos dias da promulgação do Novo Código de Direito Canônico, no discurso ao Tribunal da Rota Romana, discorreu sobre a novo Código de Direito Canônico que oferece "um claro roteiro e um válido auxílio para viver corajosamente as verdades evangélicas e a própria vocação na Igreja de Cristo". A lei canônica, "atribuindo a primazia ao amor, à graça e aos carismas, torna ao mesmo tempo mais fácil o seu orgânico desenvolvimento na vida, quer da sociedade eclesial quer também de cada um dos membros da Igreja" 14 .

O Pontífice afirmou em 1984 que o novo Código de Direito Canônico foi "fruto de longo trabalho, paciente e esmerado, enriquecido por diversas consultas do Episcopado que lhe imprimiram uma nota particular de colegialidade". $\mathrm{Na}$ verdade, este código representa um guia autorizado para a aplicação do Concílio Vaticano II e poderia, aliás, considerar-se como "o último documento do Concílio", afirmou João Paulo II. Por isso, o tempo da preparação da legislação já passou e o Código anterior foi revogado ${ }^{15}$.

Nesta perspectiva, Bento XVI afirmou que o magistério de Paulo VI e o magistério de João Paulo II seguiram a continuidade hermenêutica do Concílio como também a obra legislativa de promulgação do código latino e do código oriental ${ }^{16}$. No discurso aos membros da

13 Cito o artigo publicado sobre o tema: GERALDO, D., A jurisprudência rotal como serviço à Igreja e à humanidade nas alocuções de João Paulo II, in Scientia Canonica, v.1, n. 1, 2018, p.97-123.

14 JOÃO PAULO II, Alocução ao Tribunal da Rota Romana: A maior função da Sagrada Rota é manifestada pela exemplar qualidade do trabalho realizado, in Acta Apostolica Sedis, vol. 75 (1983) 554-559; in L'Osservatore Romano, Edição Semanal em Português, ano XIV, n. 10 (692), 6 de março de 1983, p. 9.

15 JOÃO PAULO II, Alocução ao Tribunal da Rota Romana: A fidelidade é o primeiro e mais importante dever do juiz, in Acta Apostolica Sedis, vol. 76 (1984), 643-649; in L'Osservatore Romano, Edição Semanal em Português, ano XV, n. 6 (740), 5 de fevereiro de 1984, p. 8.

16 BENTO XVI, Alocução ao Tribunal da Rota Romana: A redescoberta da beleza daquela "verdade sobre o matrimônio" que Jesus nos ensinou plenamente, in L'Osservatore Romano, Edição Semanal em Português, ano XXXVIII, n. 5 (2007), p. 5-6. 
Cúria Romana em 2005, Bento XVI considerou dois modelos de hermenêutica aplicadas ao Concílio Vaticano II: a hermenêutica da descontinuidade ou de ruptura e a hermenêutica da renovação. No primeiro modelo, da descontinuidade, os textos aprovados refletiriam apenas "de modo imperfeito o verdadeiro espírito do Concílio e a sua novidade, sendo preciso ir corajosamente para além dos textos, deixando espaço à novidade em que se expressaria a intenção mais profunda, embora ainda indistinta" ${ }^{17}$. Desse modo, seria necessário seguir não os textos do Concílio, mas o seu espírito. No segundo modelo, da renovação, o único sujeito-Igreja continua antes e depois do Concílio, mas cresce no tempo e se desenvolve, permanecendo, porém sempre o mesmo e único sujeito do Povo de Deus a caminho.

\section{A metodologia jurídico-canônica ancorada no mistério da Igreja}

Atualmente, em tantos ambientes a cultura está confusa, se não completamente perdida, em relação ao relacionamento com Deus e ao significado da vida, da existência e da morte. Essa perda de referência é refletida em nossos dias no contexto do direito canônico, com uma versão virulenta e perigosa, que todos pensávamos estar ligada ao passado, de uma antijuridicidade que, frequentemente e voluntariamente, corre o risco de se traduzir em verdadeira arbitrariedade e, portanto, de reconhecimento indevido do que é justo ${ }^{18}$.

Todavia, o decreto conciliar Optatam Totius (número 16) afirma que posição do direito canônico é o de atender ao "mistério da Igreja, segundo a constituição dogmática De Ecclesia" promulgada pelo próprio Concílio. A afirmação coloca em primeiro plano a fundamentação do direito canônico e não, necessariamente, os temas estritamente científico-técnicos. No entanto, a metodologia deve seguir a fundamentação ontológica do direito canônico apresentada no documento conci-

17 BENTO XVI, Discurso aos membros da Cúria da Romana, in L'Osservatore Romano, Edição Semanal em Português, ano XXXVI, n. 52 (2005), p. 6-8.

18 ESPOSITO, Bruno, La Costituzione Apostolica Veritatis gaudium e le sue Norme applicative: Istruzione Gli studi di Diritto Canonico alla luce della riforma del processo matrimoniale, in Ius Canonicum, vol. 60, 2020, p. 52; in file://C:/Users/Pe.\%20Denilson/Downloads/39118-Texto\%20del\%20art\%C3\% ADculo-113420-3-10-20200326.pdf 
liar. Na realidade, diante das posturas de ataque à juridicidade da Igreja, o Concílio fundamentou a natureza da ciência canônica no mistério da própria Igreja e isso tem consequências na metodologia científica canônica ${ }^{19}$.

No marco do Ano da Fé e das comemorações do cinquentenário da abertura do Concílio Vaticano II (2012), Bento XVI refletiu novamente sobre a interpretação e a aplicação da lei canônica e sua relação com a fé, "considerando que o direito canônico encontra nas verdades de fé o seu fundamento e o seu próprio sentido, e que a lex agendi não pode deixar de refletir a lex credendi", afinal a hermenêutica do direito canônico está conectada ao conceito de legislação eclesiástica. Caso houvesse a tendência de identificar o direito canônico com o sistema das leis canônicas, o conhecimento do que é jurídico na Igreja consistiria em compreender quanto estabelecem os textos legais. Esta concepção levaria a ignorar o direito natural e o direito divino, assim como a necessária relação do direito com a comunhão e a missão da Igreja, supondo uma criatividade jurídica que, na prática estaria exposta ao risco de arbitrariedades" $" 20$.

Desta forma, considerando a identificação do direito canônico com o sistema das leis canônicas, a correta hermenêutica legal dos textos legislativos no âmbito eclesial é esvaziada, pois não interessa compreender a disposição da lei, dado que ela, nesta concepção, pode ser dinamicamente adaptada a qualquer solução, também oposta ao texto. Para ilustrar e apresentar uma solução, Bento XVI fez relação com outro discurso que foi pronunciado ao Parlamento Alemão, no qual afirmou ser o direito inseparável da justiça, servindo também para lei canônica ${ }^{21}$.

19 FORNÉS, Juan, Ciencia Canónica, in Diccionario General de Derecho Canónico, Instituto Martin de Azpilcueta: Facultad de Derecho Canónico Universidad de Navarra v. II, p. 79.

20 BENTO XVI, Alocução ao Tribunal da Rota Romana: A lei canônica interpretase na Igreja, in L'Osservatore Romano, Edição Semanal em Português, ano XLIII, n. 4 (2012), p. 5 e 11.

21 BENTO XVI, Discurso ao Parlamento Alemão: Uma política ao serviço do direito e da justiça, in L'Osservatore Romano, Edição em língua portuguesa, ano XLII, n. 39 (2011), p. 4-5. 
Assim, “torna-se possível uma hermenêutica legal que seja autenticamente jurídica, no sentido de que, pondo-se em sintonia com o significado próprio da lei, pode fazer-se a interrogação crucial sobre o que é justo em cada um dos casos". Esta chave interpretativa é considerada no Código de Direito Canônico quando estabelece o uso dos meios hermenêuticos, iniciando pelo "significado próprio das palavras considerado no texto e no contexto", (cânon n. 17), não como mera prática lógica, mas como ação no corpo eclesial que permite adentrar ao verdadeiro sentido da letra da lei. Confirma-se assim que, também, na hermenêutica da lei o horizonte autêntico é o da verdade jurídica a ser amada, procurada e servida. Esta interpretação da lei canônica é elaborada na Igreja, sentire cum Ecclesia, que também adquire sentido na disciplina, em razão dos fundamentos doutrinais sempre presentes e ativos nas normas legais da própria Igreja. Daqui brota um conceito de maturidade cristã e intelectual que "leva a amar cada vez mais a lei e a desejar compreendê-la e aplicá-la com fidelidade". Para tanto, é "necessário um espírito de docilidade para respeitar as leis, procurando estudar com honestidade e dedicação a tradição jurídica da Igreja para poder identificar-se com ela" e também com as disposições legais emanadas pelo Magistério ${ }^{22}$.

Em outras palavras, o direito canônico existe para atender ao "mistério da Igreja, segundo a constituição dogmática De Ecclesia" promulgada pelo próprio Concílio. É um direito que faz parte da natureza da Igreja e não extrínseco a Ela, caso contrário, seria um conjunto legislativo unicamente organizativo das relações humanas. Porém, será necessário sempre reafirmar a autonomia da ciência canônica e dotada de método próprio que não se identifica com a teologia ou a pastoral.

\section{A limitação hermenêutica da ciência canônica como disciplina teológica}

Uma das primeiras considerações sistemáticas da ciência canônica como disciplina teológica foi da "Escola de Munique", nascida

22 BENTO XVI, Alocução ao Tribunal da Rota Romana: A lei canônica interpretase na Igreja, p. 5 e 11. 
do ensino de Klaus Mörsdorf (1909-1989). O contexto era a crise de aceitação do direito canônico nos ambientes católicos, gerada pelas aquisições da Eclesiologia e a dificuldade do próprio direito de se articular com a visão eclesiológica em que se fundamentava o Ius Publicum Ecclesiasticum. Para Mörsdorf, o direito eclesial é uma realidade teológica, que pertence intrinsecamente à Igreja. $\mathrm{O}$ mandato de Cristo, "ide por todo o mundo (...) batizai em nome do Pai e do Filho e do Espírito Santo, ensinai a cumprir tudo o que vos mandei", contém desde o primeiro instante uma normatividade. O modo de batizar e o que se ensina manifestam o caráter propriamente jurídico dos elementos com que a Igreja se constrói, isto é, com a Palavra e com os Sacramentos ${ }^{23}$.

Nesta perspectiva, o direito canônico é considerado como disciplina teológica ou a ciência canônica seria uma disciplina teológica com método jurídico. Esta tendência foi uma tentativa de superar os problemas provenientes do enfoque do positivismo jurídico e do iusnaturalismo racionalista que considerava a estrutura social e jurídica somente aquelas realidades que encontram fundamento na Palavra de Deus e nos Sacramentos, excluindo tudo que não entra nos dados sobrenaturais. Consequentemente, o método jurídico não poderia ser aplicado ao direito canônico de modo autônomo, mas subordinadamente ao método teológico.

Deste modo, continua Fornés, as demais ciências - como a filosofia, a história, a sociologia e também o direito canônico, não estão em diálogo com a teologia, mas são assumidas como ciências auxiliares da teologia. Nesta perspectiva, é necessário considerar a Igreja como uma realidade sobrenatural e não somente humana. Porém, ao mesmo tempo, é necessário não confundir a realidade sobrenatural com a ciência teológica, que possui determinados pressupostos metodológicos de uma realidade sobrenatural. Além do mais, a teologia com sua própria perspectiva metodológica, não se identifica com o método do direito canônico, que também tem a sua especificidade me-

23 CATtANEO, Arturo, Fondamenti ecclesiologici del diritto canonico, Marcianum Press, Venezia, 2011, p. 62. 
todológica, com conceitos e com terminologias típicas da ciência canônica ${ }^{24}$.

\section{A redução da ciência canônica como disciplina pastoral}

O direito canônico, considerou Paulo VI, teve uma notável influência do direito romano e do civil, mas a nova codificação canônica foi impelida a caminhar com o espírito pastoral do Concílio Vaticano II sem perder a formalidade jurídica a serviço da verdade e acessível a $\operatorname{todos}^{25}$.

Historicamente, a ciência canônica foi direcionada a dar uma resposta às críticas provenientes da visão antijurídica da Igreja que, na realidade, refletia uma visão de que o jurídico não faz parte da natureza da Igreja. Ora, uma saída para esta situação eclesial foi submeter o jurídico às necessidades pastorais. Além do mais, seria um modo de apresentar a perspectiva canônica em consonância com o espírito pastoral do Concílio Vaticano II. Contudo, nesta perspectiva o método jurídico do direito canônico continua sendo algo que desfigura a Igreja porque não faz parte de sua natureza ${ }^{26}$.

O Papa Francisco tem insistido na dimensão pastoral do direito canônico. Em suas alocuções ao Tribunal da Rota Romana, Francisco afirmou que "do juiz exige-se não apenas uma competência comprovada, mas também um espírito de serviço genuíno. Ele é o servidor da justiça (...), é animado pela caridade pastoral”. Nesta mesma alocução, afirmou que "enquanto desempenhais a vossa função judiciária, não esqueçais que sois pastores" 27 .

24 FORNÉS, Juan, Ciencia Canónica, in Diccionario General de Derecho Canónico, Instituto Martin de Azpilcueta: Facultad de Derecho Canónico Universidad de Navarra v. II, p. 80-81.

25 PAULO VI, Alocução ao Tribunal da Rota Romana: A função judiciária da Igreja ao serviço da verdade e da caridade, in L'Osservatore Romano, Edição Semanal em Português, ano II, n. 6, 7 de fevereiro de 1971, p. 1-2 e 4.

26 FORNÉS, Juan, Ciencia Canónica, in Diccionario General de Derecho Canónico, Instituto Martin de Azpilcueta: Facultad de Derecho Canónico Universidad de Navarra v. II, p. 79-88, p. 81-82.

27 FRANCISCO, Alocução ao Tribunal da Rota Romana, in Acta Apostolica Sedis, CVI (2014), n. 2, p. 89-90. 
Francisco também exige que haja "uma conversão pastoral das estruturas eclesiásticas, para oferecer o opus iustitiae a quantos se dirigem à Igreja para esclarecer a sua situação conjugal" ${ }^{\text {22 }}$. Em 2018, falando sobre a consciência, Francisco pediu que o exercício da justiça não seja reduzido a um mero desempenho burocrático, mas que o bispo, juiz nativo na Igreja que lhe foi confiada, julgue em primeira instância os possíveis casos de nulidade matrimonial. O acompanhamento pastoral e o discernimento das consciências integram a obra dos tribunais eclesiásticos. Esta obra deve ser desempenhada na sabedoria e na busca da verdade e, só assim, a declaração de nulidade produz uma libertação das consciências ${ }^{29}$.

Durante o encontro com a Sociedade para o direito das Igrejas Orientais, Francisco considerou o direito canônico essencial para o diálogo ecumênico, particularmente com a Igreja Ortodoxa e com as Igrejas Ortodoxas Orientais. Ele apresentou a natureza eclesiológica do direito, uma vez que a eclesiologia se exprime nas instituições e no direito das Igrejas. O atual diálogo teológico entre a Igreja Católica e a Igreja Ortodoxa, baseado no patrimônio canônico comum do primeiro milênio, busca precisamente uma compreensão comum do primado e da sinodalidade, com suas inter-relações, ao serviço da unidade da Igreja $^{30}$.

Desse modo, podemos dizer que para Francisco, o direito canônico, seguindo o decreto conciliar, pertence à natureza da Igreja e possui um método próprio, mas com uma finalidade pastoral.

\section{A metodologia jurídica da ciência canônica}

Paulo VI em 1972 tratou o tema da justa relação entre Igreja e direito canônico, reconhecendo, no elemento jurídico, um fator consti-

28 FRANCISCO, Alocução ao Tribunal da Rota Romana, in Acta Apostolica Sedis, CVII (2015), n. 2, p. 182-185.

29 FRANCISCO, Alocução ao Tribunal da Rota Romana, in Acta Apostolica Sedis, CX (2018), n. 2, p. 237-240.

30 FRANCISCO, Primazia e sinodalidade ao serviço da unidade da Igreja. In L'Osservatore Romano, edição em língua portuguesa, Ano L, n. 39 (2.584), terça-feira 24 de setembro de 2019, p. 5; in Acta Apostolica Sedis, CVI (2014), n. 2, p. $75-76$. 
tutivo da mesma Igreja, opondo-se a algumas interpretações que considerou abusivas do Concílio Vaticano II. Paulo VI criticou certas situações em que se "discutiu sobre a existência de um direito canônico ao ponto de qualificar como "juridicismos", com certa reprovação e ironia, todas as suas solicitudes normativas, desqualificando, portanto, este aspecto da vida eclesiástica". Na verdade, "o homem sem lei deixa de ser homem (...), sem uma autoridade que a ensine e a interprete, facilmente se torna obscura, incômoda, e desaparece". O critério evangélico da caridade é o que leva a Lei à plenitude e a nota pastoral é o fio condutor para a formulação, interpretação e aplicação do novo Código que estava sendo produzido ${ }^{31}$.

Fundamentada no decreto conciliar (Optatam Totius, 16), a possibilidade de compreender a ciência canônica a partir do mistério da Igreja, sem deixar sua especificidade jurídica-canônica, nos leva à ontologia da ciência canônica que é científica e expositiva.

Esta linha de reflexão evidencia que o direito canônico é uma expressão na história da justiça inerente à natureza da Igreja. Deste modo, a ciência canônica continua sendo um saber cientificamente jurídico, não teológico, porque será determinada a partir de uma ótica precisa, ou seja, sob a razão da justiça. Em resumo, para estabelecer o método da ciência canônica, considerando a fundamentação ontológica desta ciência no mistério da Igreja, colocada pelo Concílio, é inapropriado considerar a ciência canônica seja como disciplina teológica seja como ciência pastoral ${ }^{32}$.

\section{Uma proposta metodológica para a ciência canônica}

No período pós-concílio, Paulo VI propõe "uma nova reflexão sobre a aequitas canônica à luz do Concílio Vaticano II, para lhe conferir um valor cristão e um significado mais acentuadamente pastoral". É a ação do juiz como bom pastor para "ser vigilante não só para tute-

31 PAULO VI, Alocução ao Tribunal da Rota Romana: A justiça e a caridade no exercício da função judiciária da Igreja. In L'Osservatore Romano, Edição Semanal em Português, Ano III, N 6, 6 de fevereiro de 1972, p. 3-4.

32 FORNÉS, Juan, Ciencia Canónica, in Diccionario General de Derecho Canónico,p. 86. 
lar a ordem jurídica, mas também para curar e educar, dando provas de verdadeira caridade" ${ }^{33}$, demonstrando que sua ação é ágil, jurídica, suave e serena.

Na verdade, a crise vivida pela ciência canônica no período pósconcílio não foi superada por uma visão redutiva do direito canônico, como um mero conjunto de cânones e normas humanas formalmente em vigor ou como um simples instrumento técnico, que poderia servir para às mais diversas finalidades. É necessário entender e elaborar a ciência canônica com consequências práticas que derivam de um método para tratar questões determinadas. Em outras palavras, o canonista, que é um jurista cultivador de uma ciência prática, não aceitará fórmulas genéricas de caráter metodológico que não se apliquem às questões concretas. Assim nos perguntamos: já que a ciência canônica tem seu próprio estatuto epistemológico, qual o método apropriado para esta ciência? ${ }^{34}$.

D'Agostino diz que a relação epistemológica entre o jurista e as leis é análoga à relação entre o médico e a medicação ao paciente, mas a finalidade da medicina não é a prescrição de remédios, e sim a cura do enfermo. O jurista utiliza o método jurídico e trabalha com as leis para que, através de tais instrumentos, haja justiça nas relações interpessoais, em nosso caso, nas relações entre os membros e as instituições da comunidade eclesial ${ }^{35}$.

Na reflexão sobre o objeto formal da ciência canônica devemos considerar duas questões. A primeira questão é não ignorar que a ciência canônica é jurídica e o método a ser utilizado é, especificamente, jurídico. A segunda questão é ter a visão de que a ciência canônica é ciência jurídica se objeto de análise é a dimensão jurídica da Igreja, ou seja, não tem outro objeto senão esta realidade eclesial. Sem dúvida que a realidade jurídica da Igreja pode ser estudada também por outras ciências, por exemplo, pela teologia, pela moral, pela pastoral, pe-

33 PAULO VI, Alocução ao Tribunal da Rota Romana: A natureza e o valor das normas jurídicas na Igreja, in L'Osservatore Romano, Edição Semanal em Português, ano IV, n. 11, 18 de março de 1973, p. 6-8.

34 FORNÉS, Juan, Ciencia Canónica, in Diccionario General de Derecho Canónico,p. 84-85.

35 D'AGOStino, F., Diritto e giustizia. Per uma introduzione allo Studio del diritto, Cinisello Balsamo, 2000, p. 14. 
la sociologia, etc. No entanto, nenhuma ciência terá o método de análise específico como a ciência canônica e por objeto o direito da Igreja, ou seja, a justa relação comunitária e social do Povo de Deus, conformando a vida prática às exigências do Evangelho ${ }^{36}$.

Vieira diz que o Reino de Deus é caracterizado pela concretização da Justiça e do Direito, sobretudo no que se refere à proteção da dignidade do mais fraco e pequeno. O Direito, assim, é objeto da Justiça e a função do direito positivo - apesar de seus limites - é um meio para a instauração da Justiça que garante e mantém a comunhão. Assim, o justo é a pessoa solidária com os outros, capaz de edificar a comunidade eclesial $^{37}$.

De modo geral, o método da ciência canônica tem uma peculiaridade que deriva da especificidade do próprio objeto cujo núcleo é a Revelação. Consequentemente, o método será determinado pelo núcleo, a Revelação (fides quae), pela acolhida através da virtude da fé (fides qua) e pela direção do Magistério da Igreja ${ }^{38}$.

\section{Os estágios de conhecimento da ciência canônica}

Javier Hervada e Pedro Lombardia nos apresentam os quatro estágios de conhecimento da ciência canônica: ontológico e axiológico, científico ou científico-técnico, casuístico e prudencial. Os estágios não estão desconectados entre si, posto que seja preciso reconhecer os limites de cada estágio, mas é necessário produzir uma ciência canônica, interdisciplinar e transdisciplinar, com abordagens que auxiliem a caminhada do Povo de Deus na estrada da justiça ${ }^{39}$.

O primeiro estágio é sobre o fundamento do direito canônico, no qual o canonista se interroga sobre as últimas causas, é sobre a reali-

36 FORNÉS, Juan, Ciencia Canónica, in Diccionario General de Derecho Canónico, p. 85.

37 VIEIRA, Tarcísio Pedro, A justiça na Igreja: compreensão teológica-jurídica, in Revista Scientia Canonica, v. 1, n. 1, p. 11-38, p. 17 e 19.

38 CATTANEO, Arturo, Fondamenti ecclesiologici del diritto canonico, Marcianum Press, Venezia, 2011, p. 119.

39 HERVADA, J. - LOMBARDIA, P., Prolegómenos: introdución al Derecho Canónico, in Comentario exegético al Código de Derecho Canónico, vol. I, p. 5971. 
dade ontológica e axiológica. Aqui não há confusão com as outras ciências, de modo concreto, com a teologia. Não se trata de uma teologia do direito canônico, mas uma teoria que fundamenta a própria ciência canônica. Por ser uma ontologia do direito canônico, a noção chave é a de direito, ou seja, a base ontológica é o conceito de justiça da realidade eclesial. Diferentemente, a noção-chave para uma teologia do direito canônico, com sua específica perspectiva, é constituída pelo conhecimento de Deus e dos demais seres enquanto se relacionam com o próprio Deus pela virtude da fé ${ }^{40}$.

Todavia, o método da ciência canônica não é o mesmo método da ciência jurídica civil. Evidentemente, o Povo de Deus caminha na história sob a exigência de justiça, mas a característica da metodologia canônica será não ignorar a Revelação. Desse modo, o método jurídico para a ciência canônica não se refere ao método usado pela ciência jurídica civil, mas no contexto jurídico-canônico de uma determinada realidade eclesial, terá sempre como referência a justiça nas relações da própria Igreja ${ }^{41}$.

O segundo estágio de conhecimento do direito canônico é o científico ou o científico-técnico, conhecimento próprio da ciência jurídica em sentido estrito. Neste estágio se examinam os dados normativos, a lei promulgada, os costumes, as normas administrativas, a jurisprudência, etc. Todavia, não se interroga sobre as últimas causas, mesmo se as têm em conta, posto que a interrogação sobre a ontologia se deu no estágio anterior. O objetivo do conhecimento no estágio científico ou o científico-técnico é de construir um sistema científico que dê razões do direito eclesial, facilitando sua compreensão, sua representação e sua aplicação. O terceiro estágio é a casuística que proporciona um conhecimento teórico-prático com o propósito de solucionar, no âmbito teórico, supostos problemas práticos que foram hipoteticamente apresentados ${ }^{42}$.

40 FORNÉS, Juan, Ciencia Canónica, in Diccionario General de Derecho Canónico, p. 85-86.

41 CATTANEO, Arturo, Fondamenti ecclesiologici del diritto canonico, p. 119120.

42 HERVADA, J. - LOMBARDIA, P., Prolegómenos: introdución al Derecho Canónico, p. 61. 
Entretanto, antes do quarto estágio, como já acenamos anteriormente, verifiquemos as características da interdisciplinaridade e da transdiciplinariedade que têm sido muito utilizadas pela pesquisa científica em todos os estágios do conhecimento.

O movimento interdisciplinar, que surgiu de forma significativa na Europa na década de 1960, objetivou o intercâmbio das áreas do saber, gerando enriquecimento mútuo, mas ainda sem uma visão integrativa. Tais intenções, argumenta De Franca, ficaram claras durante o Seminário sobre a Pluridisciplinaridade e Interdisciplinaridade nas Universidades, também conhecido como Congresso de Nice, realizado na França em 1970. Desde então, a interdisciplinaridade se tornou uma exigência científica. O termo transdisciplinaridade, por sua vez, significa não só entre, mas também através de, além de, o que atravessa todas as disciplinas e se encontra entre e além de todas elas. Portanto, a transdisciplinaridade claramente não é uma nova disciplina, mas a compilação de inúmeras, reconhecendo a importância científicoanalítica de cada uma na interpretação do caso concreto, pois o verdadeiro diálogo entre os saberes e se mostra uma importante ferramenta para a análise do direito ${ }^{43}$.

Francisco afirma na Veritatis Gaudium que a interdisciplinaridade e a transdisciplinaridade, exercidas com sabedoria e criatividade à luz da Revelação, qualifica a proposta acadêmica, formativa, e a investigação do sistema dos estudos eclesiásticos, tanto no conteúdo como no método. Trata-se de uma pluralidade de saberes que correspondente à riqueza multiforme da realidade ${ }^{44}$.

O quarto estágio, que requer uma visão interdisciplinar e transdisciplinar, é o conhecimento prudencial que significa a aplicação do direito canônico à vida real, não em casos inventados, mas sobre as situações concretas da Igreja. Refere-se, portanto, ao ato de legislar, de proferir sentenças, de exercitar um direito ou cumprir uma obrigação.

43 DE FRANÇA, Nathalia Penha Cardoso de França, A insuficiência do direito internacional aos atuais conflitos da humanidade: transdisciplinariedade, in Revista de Direito Internacional e Globalização Econômica, v. 3, n. 3, 2018, p. 3956, p. 44.

44 FRANCISCO, Const. Apost. Veritatis Gaudium sobre as Universidades e Faculdades Católicas, in Acta Apostolica Sedis 110 (2018) 1-34, n. 4c. 
Em todos esses atos permanecerá sempre a atitude de prudência jurídica $^{45}$.

João Paulo II dizia que a função de juiz requer um conhecimento do fato a ser julgado e um conhecimento da nova lei que "supõe um estudo assíduo, científico, aprofundado e que não se limite a relevar as eventuais variações a respeito da lei anterior, ou a estabelecer-lhe o sentido meramente literal ou filológico, mas que chegue a considerar também a mens legislatoris et ratio legis" para entender o espírito da nova lei. Ao conhecimento segue-se a fidelidade que significa "aceitação sincera, leal e incondicionada da lei legitimamente promulgada"46.

Nesse sentido, "tudo aquilo que o Concílio propôs não se pode considerar como dito isoladamente, sem relação com as outras coisas; mas constitui uma norma verdadeira" como "instrumentos por meio dos quais os fiéis cheguem de modo ordinário e ordenado aos bens confiados por Deus à Igreja" para obter a paz com Deus e a paz humana. Rejeitando a separação entre Espírito e direito, entre a chamada Igreja pneumática e institucional, a comunhão da Igreja está dotada de estrutura jurídica, pois participa da natureza sacramental da Igreja ${ }^{47}$.

A ciência do direito canônico, elaborada a partir do método jurídico, tem um caráter unitário e deriva de um único objeto que é o direito da Igreja. O direito canônico pode ser considerado como verdadeira ciência porque possui um objeto específico e uma peculiaridade científica onde se realiza a singularidade dos seus instrumentos e dos seus recursos técnicos. Por isso, a ciência canônica nos leva a considerar os temas relativos à fundamentação do direito canônico, à luz do

45 HERVADA, J. - LOMBARDIA, P., Prolegómenos: introdución al Derecho Canónico, p. 61.

46 JOÃO PAULO II, Alocução ao Tribunal da Rota Romana: A fidelidade é o primeiro e mais importante dever do juiz, in Acta Apostolica Sedis, vol. 76 (1984), p. 643-649; in L'Osservatore Romano, Edição Semanal em Português, ano XV, n. 6 (740), 5 de fevereiro de 1984, p. 8.

47 PAULO VI, Alocução ao Tribunal da Rota Romana: Função das estruturas jurídicas na vida da igreja, in L'Osservatore Romano, Edição Semanal em Português, ano VIII, n. 7 (376). 13 de fevereiro de 1977, p. 4-5. 
mistério da Igreja, sem deixar de mostrar a dimensão de justiça inerente à própria Igreja ${ }^{48}$.

\section{Algumas indicações metodológicas para a produção jurídico- canônica}

Para a publicação de um texto científico de direito canônico é necessário que seja inteligível e com uma linguagem, ordinariamente, utilizada no universo canônico. Quem ler um elaborado científico poderá compreender sobre o que se está escrevendo e de onde foram retiradas as informações com as notas explicativas e as citações. Contudo, a produção científica é feita para pessoas da área científica e não permite repetições, pois em direito bis repetita non placent.

Em um trabalho de pesquisa cientifica, o aparelhamento crítico é decisivo e as afirmações precisam ser documentadas. As opiniões pessoais são introduzidas a partir de uma reflexão construída no texto. Buscam-se, preferencialmente, formas sintáticas impessoais, melhores do que na "minha opinião" ou semelhantes ${ }^{49}$.

O aparelhamento crítico torna-se ainda mais necessário nos excursus historicus. Neste caso, são imprescindíveis as justificativas documentais baseadas nas fontes. A citação de uma fonte não se faz a partir de um artigo ou um manual, mas a própria fonte é a referência. Pode-se utilizar também a Leges Ecclesiae post Codicem Iuris Canonici editae, os vários Enchiridion, Acta Apsotolica Sedis, L'Osservatore Romano, Comunicado Mensal da CNBB e a Sedoc. Na verdade, a cientificidade de um texto depende do modo como se apresentam criticamente as fontes, articulando ao próprio discurso a reflexão dos autores.

48 FORNÉS, Juan, Ciencia Canónica, in Diccionario General de Derecho Canónico, p. 87.

49 A Pontifícia Universidade Lateranense publicou neste ano de 2020 as Norme redazionali e orientamenti metodologici per gli elaborati accademici, $3^{\text {a }}$ edizione, com indicações práticas sobre o elaborado científico. 


\section{A atual normativa para os estudos de direito canônico}

Em 2 de Setembro de 2002 a Congregação para a Educação Católica publicou um decreto pelo qual, alterando as normas da Sapientia Christiana ${ }^{50}$ que regulavam os programas das Faculdades de Direito Canônico, procedeu a uma reforma do respectivo Plano de estu$\operatorname{dos}^{51}$. Exigiu-se uma maior preparação teológica (dois anos em vez de um) dos que desejavam aceder aos estudos da licenciatura em direito canônico sem a formação teológica básica. Aumentou-se o ciclo de licenciatura de dois anos para três. Por fim, a reforma introduziu uma nova disciplina no segundo ciclo de Licenciatura, chamada teologia do direito canônico. A novidade desta disciplina obrigou a perguntarmonos sobre qual seja a sua natureza, o seu conteúdo e o seu método, diferentemente da ciência canônica.

A Constituição Apostólica Veritatis Gaudium (Alegria da Verdade) ${ }^{52}$ sobre as universidades e as faculdades eclesiásticas da Igreja Católica, publicada pelo Papa Francisco em dezembro de 2017, reafirmou a centralidade da história para o cristianismo e o encontro com Jesus Cristo também no mundo acadêmico e científico. A história para a fé cristã é a condição para compreender a encarnação do Verbo e a natureza do Povo de Deus, enquanto peregrino pelos caminhos da história e chamado a unir-se solidariamente com a humanidade para construir uma civilização. Em consonância com uma longuíssima relação do catolicismo com o mundo acadêmico, o Papa insiste sobre a missão evangelizadora da Igreja e sua relação com o vasto e diversificado sistema das universidades e da ciência.

50 CONGREGAÇÃO PARA A EDUCAÇÃO CATÓLICA, Decreto com que se renova a ordem dos estudos nas Faculdades de Direito Canónico Novo Codice, in Acta Apostolicae Sedis 95 (2003), 2 setembro 2002, 281-285.

51 Estabeleceu-se que os artigos 76 da Constituição Apostólica Sapientia christiana e o 56 e 57 dos Regulamentos da mesma sejam mudados do seguinte modo: I. Art. $^{\circ} 76$ da Const. Apost. Sapientia christiana que alterou o currículo dos estudos de uma Faculdade de Direito Canônico e incluiu: o primeiro ciclo, o segundo ciclo e o o terceiro ciclo. II. Art. ${ }^{\circ} 56$ dos Regulamentos que determinou as disciplinas obrigatórias. III. Art. ${ }^{\circ} 57$ dos Regulamentos quem poderia ser admitido.

52 FRANCISCO, Const. Apost. Veritatis Gaudium sobre as Universidades e Faculdades Católicas, in Acta Apostolica Sedis 110 (2018) 1-34. 
De fato não há sentido em separar a fé e a vida cotidiana. $\mathrm{O}$ Concílio Vaticano II foi uma clara mensagem de superaração dessa divisão e, consequentemente, de uma interação entre a ciência produzida pela comunidade universitária e o mistério de Cristo, considerando que a compreensão da ressurreição de Jesus repercute na história da humanidade e na vida eclesial. Nesse contexto, é necessário dialogar com a cultura contemporânea e ouvir os seus problemas, conhecer suas feridas e participar de suas soluções. Podemos então dizer que não existe ciência canônica e teológica ausente da Igreja local, como não existe fé distante da realidade social.

A visão integral dos estudos na universidade, que considera a pessoa em sua totalidade e inserida em sua cultura é uma exigência da fé cristã e, por isso, uma exigência ao Povo de Deus que se prepare para a evangelização. As universidades católicas e as faculdades eclesiásticas constituem uma espécie de providencial laboratório cultural, onde a Igreja se exercita na interpretação da realidade que brota do evento Jesus Cristo e se nutre dos dons da Sabedoria e da Ciência que se tornam valores imprescindíveis para uma "Igreja em saída".

Nesse sentido, a nova Constituição Apostólica Veritatis Gaudium elenca quatro critérios para uma renovação dos estudos que contemple uma "Igreja em saída" e em diálogo com a cultura: 1. O anúncio do Evangelho é uma feliz notícia, principalmente aos pobres, brota do mistério da Trindade e propicia uma missionariedade solidária com as realidades locais e internacionais; 2. A abertura ao diálogo com a cultura não significa mera estratégia de convencimento, mas trata-se de uma exigência da vida comunitária, ou seja, da vida social e eclesial; 3. Consequentemente, a interdisciplinaridade e transdisciplinariedade das ciências, incluso o direito canônico, são princípio vital e intelectual da unidade do saber na distinção e no respeito pelas suas múltiplas, conexas e convergentes expressões, princípio capaz de realizar uma síntese orientadora para a vida, conectando os estudos com os problemas práticos do cotidiano; 4 . As redes entre as instituições católicas e laicas colaboram na promoção de estudos com abertura à internacionalização e inspiram o respeito e o cultivo das diversas tradições culturais e religiosas. 
O Título II, artigos 77-80, da Veritatis Gaudim estabeleceu que "a Faculdade de Direito Canônico, Latino ou Oriental, tem como finalidade cultivar e desenvolver as disciplinas canônicas à luz da lei evangélica, e instruir profundamente nas mesmas os alunos, para que se formem para a investigação e para o magistério, e se preparem para assumir peculiares encargos eclesiásticos" ${ }^{53}$.

Em seguida, foram publicadas as normas aplicativas da Congregação para a Educação Católica para a exata aplicação da Constituição Apostólica Veritatis Gaudium, em 27 de dezembro de 2017 no titulo II (artigos 60-63), estabelecendo que na Faculdade de Direito Canônico, Latino ou Oriental, haja a exposição científica da história e dos textos das leis eclesiásticas com seu sentido e sua conexão nos fundamentos teológicos. Foram elencadas as disciplinas obrigatórias do primeiro ciclo, do segundo ciclo e do terceiro ciclo. Também foram apresentadas as condições para a admissão de alunos provenientes de seminários e de alunos que concluíram o Direito Civil, bem como algumas indicações sobre o exame de universa iuris ${ }^{54}$.

Para ir ao encontro das novas exigências do Motu Proprio Mitis Iudex Dominus Iesus ${ }^{55}$ e do Motu Proprio Mitis et misericors Iesus ${ }^{56}$, acerca da reforma dos processos canônicos para as causas de declaração da nulidade do matrimônio ${ }^{57}$, a Congregação para a Educação Católica emanou a Instrução sobre os estudos de Direito Canônico à luz da reforma do processo matrimonial, publicado em 29 de abril de 2018. A nova Instrução considera indispensável valorizar os instrumentos normativos existentes, isto é, a Constituição Apostólica Veritatis gaudium, as Normas aplicativas anexas e o Decreto Novo

53 FRANCISCO, Const. Apost. Veritatis gaudium sobre as Universidades e Faculdades católicas, In Acta Apostolica Sedis 110 (2018), p. 30-31.

54 CONGREGATIO DE INSTITUTIONE CATHOLICA, Ordinationes ad constitutionem apostolicam Veritatis Gaudium fideliter exsequendam, in Acta Apostolica Sedis 110 (2018) 137-159.

55 FRANCISCO, Exortação Apostólica Mitis Iudex Dominus Iesus, 15 agosto 2015, in Acta Apostolicae Sedis 107 (2015), p. 958-967.

56 FRANCISCO, Exortação Apostólica Mitis et misericors Iesus, 15 agosto 2015, in Acta Apostolicae Sedis 107 (2015), 946-954.

57 RIBEIRO, V. J., A pastoral judiciária e o processo de nulidade matrimonial, in Revista Scientia Canonica, n. 1, v. 1, p. 39-70. 
Codice, nos quais são indicados os requisitos para garantir a qualidade do ensino do direito canônico, tanto nas faculdades e nos institutos de direito canônico quanto nas faculdades de teologia ${ }^{58}$.

\section{Conclusão}

Atualmente, existem 289 faculdades eclesiásticas e 503 instituições associadas (afiliadas, agregadas e incorporadas), num total de 792 institutos; 28 ateneus (com 3 faculdades eclesiásticas) e universidades (com 3 faculdades eclesiásticas) ${ }^{59}$; entre as faculdades, 160 são de teologia, 49 de filosofia, 32 de direito canônico e 40 de outras disciplinas. As instituições estão distribuídas da seguinte forma: na África tem 15 faculdades e 76 instituições associadas; na Ásia tem 25 faculdades e 56 instituições associadas; na América do Norte tem 19 faculdades e 25 instituições associadas; na América do Sul tem 22 faculdades e 56 instituições associadas; na Oceania tem 1 faculdade e 3 instituições associadas; na Europa tem 207 faculdades e 287 instituições associadas. O número de estudantes é de 64.500 e o número de professores é de $12.000^{60}$.

O Brasil é um país continental e são muitas as regiões que não possuem pessoas formadas em direito canônico. A urgente necessidade de preparação para os tribunais eclesiásticos e para os trabalhos nas cúrias passa necessariamente pela faculdade de Direito Canônico. O conhecimento científico unido à titulação de mestre ou doutor será de grande auxílio à Igreja e à sociedade brasileira.

Uma novidade na Veritatis Gaudium, pode ser adequado também à realidade brasileira, é o reconhecimento da possibilidade de realizar parte dos cursos através do ensino à distância. O impacto das novas mídias pode transformar a educação acadêmica e seus objetivos, incluindo a atualização profissional, aprendizagem ao longo da vida,

58 CONGREGATIO DE INSTITUTIONE CATHOLICA (DE STUDIORUM INSTITUTIS), Instructio studia iuris canonici sub luce processus matrimonialis reformationis, In Acta Apostolica Sedis, ano CX, 4 maii 2018, n. 5, p. 661.

59 FRANCISCO, Const. Apost. Veritatis gaudium sobre as Universidades e Faculdades católicas, art. $62 \S 2$.

60 A. V. ZANI, Principali novità normative della Costituzione Apostolica "Veritatis gaudium”. Excursus dal Concilio ad oggi, in Educatio Catholica 4 (2018) 85. 
treinamento especializado, ensino superior para estudantes de áreas distantes e formação para ordens monásticas e congregações da vida contemplativa $^{61}$.

Todavia, deve-se aprender o método de estudo, a linguagem própria da ciência, o modo de argumentar diante dos problemas eclesiais que se apresentam. O direito canônico, como foi suficientemente argumentado, tem sua especificidade e sua identidade e o canonista, que não utiliza as ferramentas do próprio direito para a elaboração da ciência, poderá apresentar um trabalho com características de outra ciência. $\mathrm{O}$ direito canônico é também pastoral com suas fontes teológicas e bíblicas, mas não se esgota em tais ciências. Para contribuir com a Igreja e a sociedade, o canonista deve saber trabalhar com as leis, com a justiça, de modo interdisciplinar e transdisciplinar, a partir da visão eclesiológica do Vaticano II. A metodologia canônica possibilita elaborar a ciência que seja jurídica e canônica.

No início exige-se assimilar um método, mas com o uso repetitivo, a metodologia começa a fazer parte daquele que se dedica a essa ciência. Surge, então, o estilo próprio de elaborar a ciência canônica. Essa característica não é uma disciplina teológica ou pastoral, mas é a característica própria do direito canônico, pois o método é parte integrante da ciência estudada.

Se os estudantes (clérigos ou leigos) querem colaborar através da ciência canônica com a Igreja Universal e Local, bem como os consagrados com suas comunidades, é preciso utilizar o método do direito canônico. Em outras palavras, a Igreja e a sociedade esperam dos juristas a aplicação do método canônico de análise, pois somente eles poderão oferecê-lo.

Nosso país continental tem um vasto campo à ciência canônica e são diversos os lugares de atuação. $\mathrm{O}$ desprezo pela ciência canônica já demonstrou ser uma via errônea, pois a direito canônico, mantendo sua autonomia como ciência e com método próprio, atende ao mistério da Igreja, conforme o decreto conciliar Optatam Totius.

61 ESPOSITO, Bruno, La Costituzione Apostolica Veritatis gaudium e le sue Norme applicative: Istruzione Gli studi di Diritto Canonico alla luce della riforma del processo matrimoniale, p. 24. 


\section{Bibliografia}

A. V. ZANI, Principali novità normative della Costituzione Apostolica "Veritatis gaudium". Excursus dal Concilio ad oggi, in Educatio Catholica 4 (2018) 85.

BENTO XVI, Alocução ao Tribunal da Rota Romana: A lei canônica interpreta-se na Igreja, in L'Osservatore Romano, Edição Semanal em Português, ano XLIII, n. 4 (2012), p. 5 e 11.

BENTO XVI, Alocução ao Tribunal da Rota Romana: A redescoberta da beleza daquela "verdade sobre o matrimônio" que Jesus nos ensinou plenamente, in L'Osservatore Romano, Edição Semanal em Português, ano XXXVIII, n. 5 (2007), p. 5-6.

BENTO XVI, Discurso ao Parlamento Alemão: Uma política ao serviço do direito e da justiça, in L'Osservatore Romano, Edição em língua portuguesa, ano XLII, n. 39 (2011), p. 4-5.

BENTO XVI, Discurso aos membros da Cúria da Romana, in L'Osservatore Romano, Edição Semanal em Português, ano XXXVI, n. 52 (2005), p. 6-8.

CATTANEO, Arturo, Fondamenti ecclesiologici del diritto canonico, Marcianum Press, Venezia, 2011.

CONGREGAÇÃO PARA A EDUCAÇÃO CATÓLICA, Decreto com que se renova a ordem dos estudos nas Faculdades de Direito Canônico Novo Codice, in Acta Apostolicae Sedis 95 (2003), 2 setembro 2002, 281-285.

CONGREGATIO DE INSTITUTIONE CATHOLICA (DE STUDIORUM INSTITUTIS), Instructio studia iuris canonici sub luce processus matrimonialis reformationis, In Acta Apostolica Sedis, ano CX, 4 maii 2018, n. 5, p. 659-682. 
CONGREGATIO DE INSTITUTIONE CATHOLICA, Ordinationes ad constitutionem apostolicam Veritatis Gaudium fideliter exsequendam, in Acta Apostolica Sedis 110 (2018) 137-159.

D’AGOSTINO, F., Diritto e giustizia. Per uma introduzione allo Studio del diritto, Cinisello Balsamo, 2000.

DE FRANÇA, Nathalia Penha Cardoso de França, A insuficiência do direito internacional aos atuais conflitos da humanidade: transdisciplinaridade, in Revista de Direito Internacional e Globalização Econômica, v. 3, n. 3, 2018, p. 39-56.

E. FOGLIASSO, Il compito apologetico del Ius Publicum Ecclesiasticum, in Salesianum 7 (1945) 49-80.

ESPOSITO, Bruno, La Costituzione Apostolica Veritatis gaudium e le sue Norme applicative: Istruzione Gli studi di Diritto Canonico alla luce della riforma del processo matrimoniale, in Ius Canonicum, vol. 60, 2020, p. 1-62; in file:///C:/Users/Pe.\%20Denilson/Downloads/ 39118-Texto\%20del\%20art\%C3\%ADculo-113420-3-10-20200326. pdf

F. M. CAPPELLO, Summa Iuris Publici Ecclesiastici, Romae 1954.

F. VERA URBANO, Derecho Eclesiástico, I, Madrid 1990, 211-215.

FORNÉS, Juan, Ciencia Canónica, in Diccionario General de Derecho Canónico, Instituto Martin de Azpilcueta: Facultad de Derecho Canónico Universidad de Navarra v. II, p. 79-88.

FRANCISCO, Alocução ao Tribunal da Rota Romana, in Acta Apostolica Sedis, CVI (2014), n. 2, p. 89-90.

FRANCISCO, Alocução ao Tribunal da Rota Romana, in Acta Apostolica Sedis, CVII (2015), n. 2, p. 182-185.

FRANCISCO, Alocução ao Tribunal da Rota Romana, in Acta Apostolica Sedis, CX (2018), n. 2, p. 237-240. 
FRANCISCO, Const. Apost. Veritatis Gaudium sobre as Universidades e Faculdades Católicas, in Acta Apostolica Sedis 110 (2018) 1-34, n. $4 \mathrm{c}$.

FRANCISCO, Exortação Apostólica Mitis et misericors Iesus, 15 agosto 2015, in Acta Apostolicae Sedis 107 (2015) 946-954.

FRANCISCO, Exortação Apostólica Mitis Iudex Dominus Iesus, 15 agosto 2015, in Acta Apostolicae Sedis 107 (2015) 958-967.

FRANCISCO, Primazia e sinodalidade ao serviço da unidade da Igreja, in L'Osservatore Romano, edição em língua portuguesa, Ano L, n. 39 (2.584), terça-feira 24 de setembro de 2019, p. 5; in Acta Apostolica Sedis, CVI (2014), n. 2, p. 75-76.

G. ALBERIGO, Storia del Concilio Vaticano II, vol. II, Il Mulino, 1996, p. 150;

G. CAPUTO, Introduzione allo studio del Diritto Canonico Moderno. I: Lo Jus Publicum Ecclesiasticum, Pádua 1978.

GERALDO, D., A jurisprudência rotal como serviço à Igreja e à humanidade nas alocuções de João Paulo II, in Scientia Canonica, v.1, n. 1, 2018, p.97-123.

GERALDO, D., A Teologia do Direito Matrimonial nas Alocuções de Bento XVI ao Tribunal da Rota RomanA. In Horizonte: Revista de Estudos de Teologia e Ciências da Religião, v.13, 2015, p.1103-1121.

GERAlDO, D., As Alocuções do Papa Paulo VI ao Tribunal da Rota Romana e sua incidência sobre sínodo da família. In Revista de Teologia e Ciências da Religião da UNICAP, v.4, 2014, p.213-236.

HERVADA, J. - LOMBARDIA, P., Prolegómenos: introdución al Derecho Canónico, in Comentario exegético al Código de Derecho Canónico, vol. I, p. 33-155.

I. MARTÍN SÁNCHEZ, La razón de ser y el objeto del Derecho Público Eclesiástico, REDC 26 (1970) 39-59. 
J. CALVO, Teoría General del Derecho Público Eclesiástico, Santiago de Compostela 1968.

JOÃO PAULO II, Alocução ao Tribunal da Rota Romana: A fidelidade é o primeiro e mais importante dever do juiz, in Acta Apostolica Sedis, vol. 76 (1984), 643-649; in L'Osservatore Romano, Edição Semanal em Português, ano XV, n. 6 (740), 5 de fevereiro de 1984, p. 8 .

JOÃO PAULO II, Alocução ao Tribunal da Rota Romana: A maior função da Sagrada Rota é manifestada pela exemplar qualidade do trabalho realizado, in Acta Apostolica Sedis, vol. 75 (1983) 554-559; in L'Osservatore Romano, Edição Semanal em Português, ano XIV, n. 10 (692), 6 de março de 1983, p. 9.

JOÃO XXIII, Sollemni allocutio, in Acta Apostolica Sedis, vol. LI (27 Februarii 1959), p. 68-69.

JOSEPH RATZINGER \& VITTORIO MESSORI, A Fé Em Crise? O Cardeal Ratzinger se interroga, Editora EPU, São Paulo, 1985.

L. SPINELLI, Il Diritto Pubblico Ecclesiastico dopo il Concilio Vaticano II, Milano 1985.

LEÃO XIII, Immortale Dei, de 1 de Novembro de 1885 (in ASS 18), p. $162-175$.

MONTINI, G. B., Intervenção na XXXIV Congregação Geral, in Acta Synodalia Sacrosancti Concilii Oecumenici Vaticano II, 5 de Dezembro de 1962, v. I, Periodus Prima, Pars IV, Congregationes Generales XXXI-XXXVI, p. 292

P. LOMBARDIA, na sua síntese histórica in AA.VV. Derecho Eclesiástico del Estado Español, Pamplona, EUNSA 1980, 104-128.

PAULO VI, Alocução ao Tribunal da Rota Romana, in Acta Apostolica Sedis 58 (1966) 152-155; In GOMES, SATURINO (Org.), Alocuções dos Papas Paulo VI e João Paulo II ao Tribunal da Rota Romana, Lisboa, Universidade Católica, 2006, p. 41-44. 
PAULO VI, Alocução ao Tribunal da Rota Romana, in Acta Apostolica Sedis 61 (1969) 174-178; In GOMES, SATURINO (Org.), Alocuções dos Papas Paulo VI e João Paulo II ao Tribunal da Rota Romana, Lisboa, Universidade Católica, 2006, p. 55-59.

PAULO VI, Alocução ao Tribunal da Rota Romana: A função judiciária da Igreja ao serviço da verdade e da caridade, in L'Osservatore Romano, Edição Semanal em Português, ano II, n. 6, 7 de fevereiro de 1971, p. 1-2 e 4.

PAULO VI, Alocução ao Tribunal da Rota Romana: A justiça e a caridade no exercício da função judiciária da igreja, in Acta Apostolica Sedis 64 (1972) 202-205; In L'Osservatore Romano, Edição Semanal em Português, ano III, n. 6, 6 de fevereiro de 1972, p. 3-4.

PAULO VI, Alocução ao Tribunal da Rota Romana: A natureza e o valor das normas jurídicas na Igreja, in L'Osservatore Romano, Edição Semanal em Português, ano IV, n. 11, 18 de março de 1973, p. 68.

PAULO VI, Alocução ao Tribunal da Rota Romana: Função das estruturas jurídicas na vida da igreja, in L'Osservatore Romano, Edição Semanal em Português, ano VIII, n. 7 (376). 13 de fevereiro de 1977, p. 4-5.

PONTIFICIA UNIVERSITÀ LATERANENSE, Norme redazionali e orientamenti metodologici per gli elaborati accademici, $3^{\text {a }}$ Edizione, Roma, 2020.

REDAELLI, C., La canonistica nel contesto delle scienze teologiche, in Quaderni di diritto ecclesiale, $n$. 10 (1997), 28-39.

RIBEIRO, V. J., A pastoral judiciária e o processo de nulidade matrimonial, in Revista Scientia Canonica, n. 1, v. 1, p. 39-70.

VIEIRA, Tarcísio Pedro, A justiça na Igreja: compreensão teológicojurídica, in Revista Scientia Canonica, v. 1, n. 1, p. 11-38. 